\title{
Gender Differences in Response to Motor Skill Training on the Performance of Dressing as an Activity of Daily Living by Pupils with Cerebral Palsy in Kisumu, Kenya
}

\author{
Janet Auma Odhiambo
}

Joy land Special School, P.O. BOX 1790, 40100, Kisumu, Kenya

Email:odnette@yahoo.com

\section{Dr. Charles Omoke}

Department of Special Needs Education, Jaramogi Oginga Odinga University of Science and Technology

\author{
Dr. Peter J. O. Aloka
}

Department of Psychology, Jaramogi Oginga Odinga University of Science and Technology

\author{
Doi:10.5901/jesr.2016.v6n1p178
}

\begin{abstract}
The study explored gender differences in response to motor skill training on curbing activity restriction of dressing by pupils with cerebral palsy in a special school in Kisumu, Kenya. Mixed method approach was adopted within which a Sequential Explanatory design was used. The sample size was 6 pupils with cerebral palsy, 6 parents of pupils with cerebral palsy, 3 teachers in charge of pupils with cerebral palsy, and 2 physiotherapists. Interviews and observational checklists were used for data collection. Quantitative data was analyzed using both descriptive and inferential statistics with the use of Mann Whitney $U$ Test. The qualitative data was analyzed through thematic analysis. The findings of the study indicated that male participants had slightly higher rank than their female counterparts in the performance of dressing ability after training. However, the ability of their performance depended much on the severity of their disability rather than gender. The study recommends that the Kenyan government should post physiotherapists in special schools for the physically challenged so that they could enhance motor skill training on learners with cerebral palsy.
\end{abstract}

Keywords: Gender, Dressing, Activity restrictions, brain, functional difficulties.

\section{Introduction}

Cerebral Palsy (CP) can be described as the damage done to human brain during infancy which results into activity restrictions. The destruction of certain parts of the brain is usually caused by lack of normal development of the brain that happens while an infant's brain has not fully developed. The interference with brain development can happen before a child is born, in the process of giving birth or shortly after birth. The damage done to the brain cannot be repaired but can be managed through other medical strategies. Through motor skill training and development of effective prosthetic devices, pupils with cerebral palsy may no longer depend on others for support in the performance of activities of daily living. Since friendship is often gender segregated, boys tend to forge friendship with boys and girls with girls (UNESCO 2006), and the code is to help one another. Stereotypes about girls being fragile and dependent, combined with the condition of cerebral palsy may cause girls with cerebral palsy feel discouraged to risk going through physical training programs that may solve their problems of relying on peers for help.

In developed worlds, women have been reported to have significantly higher rates of functional difficulties than men (Kaplan, Anderson \& Wingard, 2002). Although some analysts have attributed this female functional disadvantage to higher prevalence of non-fatal but disabling conditions such as cerebral palsy, autism and epilepsy among others (Zunzunegui,Alvrado).

Beland, and Vissandjee, (2009), have pointed out that, even when disabling conditions are controlled, females still report higher levels of functional disability. The higher disabling functional ability among women however, may be a reflection of heightened female sensitivity to symptoms as a result of gender- specific social expectations. In USA, studies in self-reported Activities of Daily Living among men and women consistently reported more limitations on females than their male counterparts, with the greatest gender difference being reported for the gross motor mobility 
limitations, and smallest for personal care items (Romeo, Cioni \& Battaglia, 2011). Gender differences in reporting Activities of Daily Living may be affected by the gender specific nature of certain activities, with women being more likely to report difficulty in performing an activity while men may be more likely to report that they can easily do a task even if they are not able to. Having had an observed physical performance to ascertain the gender influence in response to motor skill training for the performance of Activities of Daily Living was therefore necessary. However, there was need to be cautious in interpreting gender differences in observed physical performance in the performance of dressing as an activity and extrapolating from them to gender differences in true underlying performance. The observed performance may have been affected by a variety of influences such as the severity of disability on an individual. Other factors could have been societal influences such as the gender specificity of certain activities of daily living and differences in the perception of response categories by male and female (Andrado,Guevara,Lebrao, Duarte \& Santos, 2011).

\section{Theoretical Framework}

Gender socialization theory by Michael, (2014) was applied in the study. Gender socialization is the process by which male and female acquire knowledge and acceptable ways of life within a society. Gender socialization process begins before a child is born when the parent become anxious to know whether the baby is a boy or a girl and continues throughout ones' life. Gender differences are a mixture of social and ability of an individual to take care of himself or herself in the essential daily life activities. The society can traditionally socialize male into masculinity and female into femininity. This is done by displaying masculine gender roles to be characterized by courage, independence and aggressiveness while feminine gender roles are characterized by submission, sensitivity, weakness, dependency and passiveness. During child development, both boys and girls almost progress at the same pace from dependency to independency. The age at which both sexes start to sit, crawl, walk and teeth occur at about the same time. However, girls mature to puberty a few years earlier than boys. This demands that they be able to practice self-care earlier than boys.

The barriers in the environment around children with cerebral palsy are usually stressful to the children's ability to participate in essential daily activities. Biological aspects of transition from childhood to adulthood are devastating in both boys and girls with cerebral palsy and have a high possibility of affecting their psychological well being. Whereas hormonal changes contribute to depression in youths, self esteem is another source of depression at teenage, more so on girls. Traditionally in most communities, it is believed that boys are associated with activities that require a lot of strength, while girls are assigned duties that require less energy. Physical gender differences influence the division of labor between male and female. However dressing is a universal activity for both sexes. Activities of personal care such as bathing, feeding, toileting and dressing are essential features for both male and female. It is believed that since females are better performers in multitasking than their male counterparts, girls could also be fast learners in the performance of daily activities than boys. However, this does not apply to children with cerebral palsy. Children with cerebral palsy's ability to learn a new skill entirely depends on the severity of the impairment and not their gender. All babies are aided in the performance of self care during infancy but as they grow up they learn to perform various activities of daily living by imitating adults around them. Children with cerebral palsy however, have impairments that hinder them from learning the daily living activities like their able bodied peers and therefore depend on others for help. On maturity, girls do experience their menstrual cycle once every month and would feel embarrassed being helped in that state, they would therefore strive to learn certain activities of daily living given the opportunity to do so.

Children with cerebral palsy eventually grow up into adults with cerebral palsy. At puberty they realize that activities such as, dressing, bathing and toileting need to be done in privacy. Knowing the relevance of learning the skills necessary for the performance of these activities, the children develop the interest to learn these skills and the intentionality leads to skillfulness when they are trained on it. This can be used to understand the emotions one experiences during the learning process. It aids the learner to stay motivated however tough the skill may be. It also helps the trainer to encourage the learners understand their emotions in the process of learning a new skill.

\section{Literature Review}

Merrit and Fisher (2005) conducted a study in Europe on gender difference in the performance of ADLs at Arch Ned Rehabilitation center. The study was carried out with a population of 20 patients sampled through systematic random sampling. The result demonstrated an observable difference between men and women where by men had higher ADL motor ability while women had higher ADL process ability. The results suggested that the AMPS is free of gender bias, 
although differences were found between men and women in mean ADL motor and process ability, they were not considered clinically detectable differences. The study above was on parents in a rehabilitation centre and not learners with cerebral palsy in a learning institution as was in the present study.

Livingstone, Stewart, Rosenbaum and Russel, (2011) carried out a study in Denmark on difference in learning the activities of daily living between boys and girls. A population of 120 students, sampled through stratified random sampling was involved in the study. The study showed that girls were identified as fast learners in the activities of daily living as compared to boys. Children with deficiency in daily living skills are referred to physiotherapist and occupational therapist and the results have shown so far that girls respond faster than boys. Similarly, Donkerroot, Roebroek, Wiegenrik, Vander, Maesen and Stam (2007) investigated the identification of upper extremity related ADLs by children with cerebral palsy in Africa, with the use of occupational therapy and physiotherapy. A population of 8 children with cerebral palsy sampled through convenience sampling was involved in the study. The study employed both qualitative and quantitative approaches. The findings revealed that the most preferred goals among children with cerebral palsy differed with gender; boys liked leisure related goals, while girls preferred personal care related goals.

Andrade, Guevara, Lebrao, Duarte and Santos (2011) determined gender difference of disability regarding activities of daily living in life expectancy. The study findings showed that better cognitive performance and hand grip strength were protected factors among men and women respectively. The findings however explain that decreased mobility balance and health conditions that affect central nervous systems or lead to impaired cognition disable men more, whereas sedentary lifestyle, reduction in muscle strength and conditions that affect the osteoarticular system disable women more than men. Men were however more difficult to rehabilitate than women.

In Kenya Nicole, (2010) studied daily living skills by gender, with a population of 24 children with physical disabilities sampled through systematic random sampling. The study findings revealed that although boys and girls do not differ in their self-care abilities, boys were more likely than girls to have high functional cognitive skills. However, girls were more than twice more likely to score high on the self - care activities of daily living and the household responsibilities than boys.

Based on the related literature reviewed, there is scanty information on gender differences in response to motor skill training as an intervention on activity restrictions. The majority of previous studies have examined the general performance of boys and girls in activities of daily living using quantitative approach leaving out the qualitative perspective. Furthermore most of the reviewed studies have failed to establish the complexity of learning a new skill between boys and girls. Most of the reviewed studies have concentrated on the general performance on cognitive abilities among children with cerebral palsy with no information on dressing as a specific activity between boys and girls. Furthermore, most of the reviewed studies were hospital based with no information available on effects of gender differences in response to motor skill training among pupils with cerebral palsy in learning institutions. The present study concentrated on generating information on the gaps mentioned.

\section{Goal}

The study examined gender differences in response to motor skill training for curbing activity restriction by pupils with cerebral palsy in a special school in Kisumu, Kenya

\section{Methodology}

\subsection{Design}

Mixed methods approach was used, with which a Sequential Explanatory study design was employed. Quantitative approach involved the use of numbers to asses information which was then evaluated using statistical analysis which offered the opportunity to dig deeper into data and look for the greater meaning (Oso \&Onen, 2008). Quantitative data was collected first, followed by qualitative data, then interpretations done. The quantitative approach adopted an experiment for data collection.

\subsection{Participants}

Targeted population was 14 pupils with cerebral palsy, 23 teachers of pupils with physical disabilities in a special school for the physically challenged, 14 parents of pupils with cerebral palsy, and 2 physiotherapists. Seventeen (17) 
respondents participated in the study, these included, 6 pupils with cerebral palsy, 3 teachers in charge of pupils with cerebral palsy in the school, 6 parents of pupils with cerebral palsy, and 2 physiotherapists.

\subsection{Sample size}

The sample size was six (6) pupils with cerebral palsy at a special school, three (3) teachers handling pupils with cerebral palsy in the school, six (6) parents of pupils with cerebral palsy and two (2) physiotherapists all through purposive sampling procedures.

\subsection{Research Instruments}

The primary source of data in the study was through the use of observational checklist. Supporting data was collected with the use of interview schedules by the teachers, parents, and physiotherapist. Validity of questionnaires was ensured through expert judgment that is with the help of lecturers, while reliability was tested using internal consistency and a reliability coefficient of 0.866 was reported.

\subsection{Procedure for data collection}

All the relevant authorities gave consent for the study to be carried out, these included, Board of post graduate studies of Jaramogi Oginga Odinga University of science and Technology, National Council of Science and Technology, Ethical approval committee, County Education Office, schools' principal and parents of children with cerebral palsy. The performance of dressing as an activity by pupils with cerebral palsy was assessed in three different stages. A pre- test was done with twelve pupils with cerebral palsy on their performance of specific activities. The pre-test assessed the pupils level of performance in dressing related activities before any training. The pupils were then divided into two equal groups, six in a group to get trainings and another six in a group which was not to get any motor related training. The group to be trained had three boys and three girls. Motor skill training programs were administered to them for three months and their progress observed and recorded. A post test was carried out for the six pupils and a comparison made between the performance of boys and girls. Analysis was then made and recorded.

\subsection{Data analysis}

Quantitative data was analyzed using both descriptive and inferential statistics with the use of Mann-Whitney U Test, through the statistical package for Social Sciences (SPSS) version 20, all tests of significance were computed at $a=$ 0.05. Inferential statistics was purely focused on the non-parametric methods. The researcher created a Microsoft word file for the observations made and the observations documents were analyzed for each case. The findings were presented using graphs. Qualitative data was analyzed through thematic analysis to determine the themes, trends and opinions expected, considering the range and diversity of participants experiences and perceptions. It was done through the process of coding in six phases as recommended by Braun and Clarke, (2006), which created and established meaningful patterns which included; familiarization with the data, generating initial codes, searching for themes among the codes, reviewing themes, defining and naming themes and the final report produced. Verbatim quotations were also included to show feelings of the participants.

\section{Finding}

Gender difference in response to motor skill training on the performance of dressing as an Activity of Daily Living by pupils with cerebral palsy was established. To address this, non-parametric test, Mann-Whitney U Test, was used to test whether there was any statistical significant difference in performance in dressing of children with cerebral palsy. MannWhitney $\mathrm{U}$ Test, which is the non-parametric alternative to the t-test for independent samples, was used to test for differences in acquisition of fine motor skills related to dressing between the two independent groups; males and females. Instead of comparing means of the two groups, as in the case of the t-test, the Mann-Whitney U Test compared medians of the two groups. The scores on the continuous variable were converted to ranks, across the two groups. It was then evaluated whether the ranks for the two groups differ significantly. The results are presented in Table 1. 
Table 1: Ranks of dressing skill acquisition in relation of gender

\begin{tabular}{|c|c|c|c|c|}
\hline & Gender & N & Mean Rank & Total Ranks \\
\hline \multirow{3}{*}{ Post-Test } & Boys & 3 & 4.00 & 12.00 \\
& Girls & 3 & 3.00 & 9.00 \\
& Total & 6 & & \\
\hline
\end{tabular}

The findings in Table 1, shows the ranking of mean dressing abilities, which indicates that, the male participants had slightly higher rank than their female counterparts in dressing ability after training. However, an interpretation of results from Mann-Whitney U Test, in the SPSS output in Table 2:, do not support this argument.

Table 2: Mann-Whitney Test Results

\begin{tabular}{|l|c|}
\hline & Post-Test Results \\
\hline Mann-Whitney U & 3.000 \\
Wilcoxon W & 9.000 \\
Z & -.664 \\
Asymp. Sig. (2-tailed) & .507 \\
Exact Sig. [2*(1-tailed Sig.)] & $.700^{\mathrm{b}}$ \\
\hline
\end{tabular}

a. Grouping Variable: Gender

b. Not corrected for ties.

Given the fact that the sample size was less than 30 , the value (-.664) for a Z-approximation test, with a significance level of $p=.507$ (Asymp. Sig; 2-tailed), did not include a correction for same scores in the data. The probability value (p) was greater than .05, indicating the result was not significant. This implies that there was no sufficient evidence to reject the null hypothesis, that there was significant difference among gender. Consequently, it was plausible to conclude that there was no statistically significant difference between males and females in the response to motor skill training on the performance of dressing as an activity of daily living by pupils with cerebral palsy in a special school for the physically challenged.

\section{Discussion}

The descriptive statistical findings of the study on gender influence on the response to motor skills training indicated that male participants had slightly higher rank than their female counterparts in dressing ability after training. However this could have been influenced by the severity of the disability on the girls in the study more than that in the boys and not their gender. However, the inferential statistical results reported that there were no significant gender differences in response to motor skill training among learners with cerebral palsy. A study by Livingstone, Stewart, Rosenbaum, and Rassel, (2011) however showed that girls have been identified as fast learners in the activities of daily living than boys. Donkerot, Roebroeck, Wiegeninks, Vander and Stan, (2007) on the other hand reported that the most preferred goals among children with cerebral palsy differed with gender. It revealed that boys liked leisure related goals, while girls preferred personal care related goals. A research by CDC (2006) revealed that men were more difficult to rehabilitate than women. Nicole (2010) similarly observed that whereas boys with physical disabilities were more likely than girls with physical disabilities to have high functional cognitive skills, girls were more than twice as likely to score high on the selfcare activities of daily living and the house hold responsibilities than boys. Summers, Larkin and Dewey (2008), in agreement revealed that boys with cerebral palsy were more comfortable being helped with the performance of the activities of daily living such as bathing, dressing, toileting and feeding than girls with cerebral palsy. This could be attributed to some cultural practices in some African countries whereby girls are expected to do all house hold chores as boys rest. On the other hand on maturity, girls usually experience their menstrual cycle once every month, a situation that would make them feel embarrassed being helped, and they would therefore strive to learn certain activities of daily living however difficult it might. 


\section{Concluding Remarks}

There was no sufficient evidence to prove the influence of gender difference in response to motor skill training on the performance of dressing as an activity of daily living. Their performance was instead dependent on how severe or mild the disability was on an individual. The performance of dressing as an activity proved to be difficult for pupils with cerebral palsy of all sexes even after training. The study however, concludes that, the motor skill training could be an effective remedy to both boys and girls with cerebral palsy in enhancing their ability to live independent lives.

\section{References}

Alexandre, T., S, Ligiana, P,C., Daniella P.N., Jair, L.F.S., Yeda, A.O.D. and Maria, L.L. (2012)."Gender differences in incidence and determinants of disability in activities of daily living among elderly individuals: SABE Study. Archives of Gerontology and Geriatrics.

Andrade, F., Guevara, P., Lebrao,M. Duarte, Y. and Santos, J. (2011). Gender differences in life expectancy and disability free life expectancy. Women Healthlssues 21 (1):64-70.Centre for Disease Control and Prevention.(2006). Prevalence of cerebral palsy - Autism and Developmental disabilities monitoring network. MMWR; Surveillance. 61(3) 1 - 9.

Belon, A.,Margaret, K.,and Marilisa, BA. (2014). "Gender differences in healthy life expectancy among Brazilian elderly", Health and Quality of life outcomes.

Centre for Disease Control and Prevention ( 2006). Prevalence of Cerebral Palsy- Autism and Developmental Disabilities monitoring netwirk. MMWR. Survelliance. 61(3): 1-9.

Galanznik, Aaaron, Jonathan, C., Jeffrey, V.,Shirani, T.,Kelly, H.Z., and Geofrey, M. "Burden of smoking on quality of life in patients with chronic obstructive pulmonary disease," Expert review of Pharmacoecomics and outcome Research, 2013.

Donkervoort, M., Roebroeck, M., Wiegeninks, D., Van der Helijden, H.\&Stam, H. (2007).Determinants of function of adolescents and young adults with cerebral palsy. Disability and Rehabilitation. 29(6): 453-463.

Gender differences in functioning for older adults in rural Bangladesh. The journals of Gerontology Series. A Biological Sciences and Medical Sciences, 2000.

Hancock, R., Rut, H. and Stephen, P. and Francesca, Z.(2015). Do household surveys give a coherent view of disability benefit targeting?: a multisurvey latent varable analysis for the older population in Great Britain. Journal of the royal statistical society.

Kaplan,RK, Anderson, JP., \& Wingard DL (2001). Gender differences related quality of life. Health Psychol: Family Medicine, University of California: San Diego.

Livingston.M.H., Stewart, D., Rosenbaum, P. and Rassel, D.J (2011). Exploring issues of participating among adolescents with cerebral palsy: Physiocupp. Ther. Pediat. 3(3):275-287.

Maas., Josina, C., Annet, J.D., Peter, A.H., Janice, E.B., Petra, J.K., Richaed, T.J.,and Jules, G.B., (20120. "Splint: the efficacy or orthotic management in rest to prevent equinus in children with cerebral palsy, a controlled trial" BMC Pediatrics.

Merrit, BK. (2003). Gender differences in the performance of activities of daily living. Archives of Physical Medicine and Rehabil 84(12); 187-198.

Michael, J. Carter. (2014). Gender Socialization and identity Theory. California University, North ridge. Avail. at. www.mdpi.com

Monserud, M.A., and R. Wong. (2015)" Depressive Symptoms Among Older Mexicans: The role of Widowhood, Gender, and Social Integration, Research on Aging.

Nicole, J. (2010). Whilewomen weep. Development of Education in Kenya for the physically disabled. Nairobi Initiatives Limited.

Oso, W.Y., and Onen, D. (2008). A general guide to writing research proposal a report. A hand book for beginning researchers (2nd ed). Kampala Uganda: Makerere University printers.

Pervin, R., Shafi, A., Rummy, T.H., Nazma, Y., Mizanur, R. and Farooquil, I. (2015)." Cerebral Palsy, an update," Northern International Medical College, Journal.

Romeo, DM.,Cioni, M., and Battaglia, LR., (2011).Spectrum of gross motor and cognitive functions in children with cerebral palsy: Gender differences. Eur. Paediatr. Neurol.87(3):378-394.

Rosenbaum, P. (2003). Controversial tratment of Spasticity: Exploring alternative therapies for motor function in children with cerebral palsy. Jchild Neural: 18: 89-94.

Rosenbaum, P., Panneth, N., Lewinton, A.,Goldstein, N., \& Bax, M. (2007). The definition and classification of cerebral palsy Developmental Medicine and Child Neurology ; 52(3): 367-378.

S. Skumlien. (2006). "Gender differences in the performance of activities of daily living among patients with chronic obstructive pulmonary disease", Chronic Respiratory disease.

Tareque, M.I., S. Begum, and Y. Saito. (2013)"Gender differences in Disability- Free Life at old Ages in Bangladesh", Journal for Aging and Health.

UNESCO,(2006). Education for All. Global monitoring report (2006). Literacy for use. Paris.

Zunzunegui, MV., Alvarado BE., Beland, F., and Vissandjee, B.(2009). Explaining health differences between men and women. Soc. Sci. Med. 68(2):235-423. 